\title{
Engineering Characteristic and Numerical Solution of Applied Mechanics on Three Sorts of Real Raindrops
}

\author{
Shijun $\mathrm{Xu}^{1, \mathrm{a}}$ and Xiaoling Ren ${ }^{2, \mathrm{~b}}$ \\ ${ }^{1}$ School of Science, Xi'an Technological University and Xi'an Jiaotong University, Xi'an, China \\ ${ }^{2}$ School of Computer, Xi'an Polytechnic University, Xi'an, China \\ axushijun000@sina.com, ${ }^{b}$ renxiaoling2@163.com
}

Keywords: atmosphere science, engineering characteristic, raindrops, terminal speed, t-test

\begin{abstract}
Taking Xi'an region for example, four influence factors on real raindrops falling in the Earth atmosphere were studied theoretically. Three groups equations of raindrops established with the Newton's dynamic equation in standard coordinate system were numerically solved through the MATLAB. For the small, middle and big raindrops, the terminal speeds reach the ranges within $(2.1-5.6 \mathrm{~m} / \mathrm{s}),(6.0-8.5 \mathrm{~m} / \mathrm{s})$ and $(8.7-10.5 \mathrm{~m} / \mathrm{s})$, and corresponding to the falling height scales of $(1.0-8.0 \mathrm{~m}),(8.2-17.0 \mathrm{~m})$ and $(22.0-33.0 \mathrm{~m})$, as well as the eastward migration ranges of $(170-590 \mathrm{~m})$, $(90-150 \mathrm{~m})$ and $(55-75 \mathrm{~m})$, and corresponding to the southward migration scales of $(3.2-16.0 \mathrm{~m})$, $(1.0-2.1 \mathrm{~m})$ and $(1.7-0.9 \mathrm{~m})$, respectively. As per the t-test and Poisson coefficient, the above three models are favorable. The theoretical research will promote water conservation in the Loess Plateau.
\end{abstract}

\section{Introduction}

As aware of the severe hazards of soil erosion, much attention and interests were concentrated to soil erosion for terminal speed, kinetic energy and influence factors on the raindrops falling in the Loess Plateau slope land ${ }^{[1-2]}$. But the detailed researching materials about the characters or laws of raindrop movement is little, only some low precision research and the ideal model ${ }^{[3-5]}$. Therefore, the studies on quasi-real raindrops movement mathematical model and its computer simulation will not only support the theoretical research of the dynamic model in the soil and water conservation in Loess Plateau, but also enrich and perfect the detailed data of the above movement in theory and experiment.

For quasi-real raindrops in the northern hemisphere atmosphere, we studied four influencing factors such as gravitational force, floating force, Coriolis force and viscous resistance in Xi'an region, established the dynamics equations of raindrop movement, proposed and compared all numerical solutions with the experimental data of soil and water conservation.

\section{Basic Engineering Characteristics on Real Raindrops Falling}

\section{Diameter of Raindrops}

The diameters of liquid raindrops from the clouds to land vary generally within $0.5-6 \mathrm{~mm}$. Because the drizzle is a special form with small and uniform rainfall, which diameters spread for $0.2-0.5 \mathrm{~mm}$, the drizzle is not considered in our work. Our studies include small raindrops of diameter $0.5-1.5 \mathrm{~mm}$, middle raindrops of diameter1.5-4.0 $\mathrm{mm}$ and big raindrops of diameter $4.0-6.0 \mathrm{~mm}$. When the raindrops diameter is greater than $6 \mathrm{~mm}$, the air resistance will be more than its molecular cohesion which keeps a raindrop complete, therefore, big raindrops will be separated into small raindrops ${ }^{[6]}$.

\section{Temperature Distribution of Convection Layer of the Atmosphere}

According to the theory of atmospheric physics ${ }^{[6]}$, within the range of the convection layer in the mid-latitude zone, the gradient of temperature is $-6.5^{\circ} \mathrm{C} / \mathrm{km}$, so that the expression of the air temperature with respect to height $h$ is

$T=288.15-0.0065 h(\mathrm{SI})$

Height of Rainfall 
According to the prediction models applied to the radio space communications systems design and the stratospheric height information at temperature $0^{\circ} \mathrm{C}$ under the rainfall conditions, the Consultative Committee of International Radio usually uses the following model to estimate the rainfall height ${ }^{[7]}$

$h_{\mathrm{FR}}(\mathrm{km})=5-0.075(\theta-23) \quad \theta>23$, in the Northern Hemisphere

where $\theta$ is the latitude, the unit name of $\theta$ is "degree". In the northern hemisphere, making use of the Xi'an latitude $34^{\circ}$, the calculation value of the rainfall height in Xi'an zone is $4175 \mathrm{~m}$.

Density Distribution of the Air

Because of the Earth gravitational field, the molecular number density $n$ in the atmosphere around the Earth decreases while height increases. Based on the laws of the Boltzmann molecular distribution, the density distribution of air can be expressed as

$\rho(z)=\rho_{0} \exp \left(-m_{0} g z / k T\right)$

where $\rho_{0}=1.225 \mathrm{~kg} / \mathrm{m}^{3}$ at the height of $0, k=1.38 \times 10^{-23}(\mathrm{SI}), m_{0}=(0.029 / 6.02) \times 10^{-23} \mathrm{~kg}$.

\section{Four Elements on Real Raindrops Falling}

\section{Gravitational Attractive Force}

The expression of the universal gravitational force is $F_{\mathrm{g}}=G M \mathrm{~m}(R+\mathrm{z})^{2}$. Where $G=6.67 \times 10^{-11} \mathrm{Nm}^{2} / \mathrm{kg}$, $M$ and $R$ are the mass and the radius of the Earth respectively, $z$ is the height of the raindrops from the ground, $m$ is the mass of a raindrop. Because of the Earth's self-rotation, the gravitational force can be decomposed into gravity and a centripetal force perpendicular to axis making uniform circular motion. The centripetal force is $F=m \omega^{2}(R+h) \cos \theta$, which is very small about $0.3 \%$ compared with the gravity. Where $\omega$ is angular velocity of the Earth's self-rotation, $\theta$ is the rainfall latitude. While raindrops are subject to constant force in later study, the gravitational force is equal to the gravity.

\section{Floating Force}

According to the Archimedes buoyancy law, the expression of buoyancy of raindrops is $F_{\mathrm{f}}=(4 / 3) \rho \pi g r^{3}$. Where $\rho=\rho_{0} \exp \left(-m_{0} g z / k T\right)$ is the air density as shown in section 1.3 .

\section{Coriolis Force}

We take a standard coordinate system as shown in Figure1. Coriolis force is an inertia force when an object moves relative to the rotating Earth reference frame, and the force can be written as

$$
\vec{F}_{\mathrm{c}}=-2 m \vec{\omega} \times \vec{v}=2 m \omega \sin \theta \frac{d y}{d t} \vec{i}-2 m\left(\sin \theta \frac{d x}{d t}+\cos \theta \frac{d z}{d t}\right) \vec{j}+2 m \omega \cos \theta \frac{d y}{d t} \vec{k}
$$

Where $m$ is the mass of a raindrop, $m=(4 / 3) \rho_{\text {water }} \pi r^{3}, \omega$ is angulacr velocity of the Earth's self-rotation, $\omega=7.27 \times 10^{-5} \mathrm{rad} / \mathrm{s}$, and $\vec{v}$ is the velocity of the raindrops. Because of the relation $\vec{v} \perp \vec{F}_{\mathrm{c}}$, the Corciolis force does not change

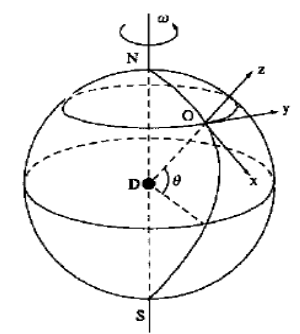

Fig.1. The Cartesian coordinate system of rainfall the speed of the moving raindrop.

In Figure 1, let the earth axis and center and direction of self-rotation angular velocity be SN and D and " $\mathrm{S} \rightarrow \mathrm{N}$ " respectively, the Cartesian coordinate system fixed on the ground be oxyz. The raindrop position project to the origin "o" at initial moment, the ox axis pointing to the South is tangent to the meridian, the oy axis pointing to the East is tangent to the latitude line, the oz axis is the line jointing the center of the earth and the origin, which direction is vertical upward. The latitude of the origin point $\theta$ is also the angle between oz axis and the equatorial plane. The unit vectors in three directions are $\vec{i}, \vec{j}$ and $\vec{k}$ respectively.

\section{Viscous Resistance}

Any fluid flowing always possesses viscous characteristic, the viscous resistance is known as the "internal friction". In falling process, the viscous resistance acting on the raindrop is a variable force depending on the size and the shape, the falling speed, the air temperature, the density and the viscosity coefficient, and so on. The force is expressed in $F_{\mathrm{r}}=\rho C_{d} S v^{2} / 2$. Where $\rho$ is air density, $S$ is the area of the object projected to a plane which is perpendicular to the velocity vector, $C_{\mathrm{d}}$ is the 
resistance coefficient related to its size and geometry shape, and so on. After the studying the range ${ }^{[6-7]}$ of Reynolds number $R_{\mathrm{e}}$ of raindrops fluid regarded as spherical bodies, we get the values of $F_{\mathrm{r}}$ of raindrops as $0.023 \rho^{0.5624} \pi r^{1.5624} v^{1.5624}, 0.250 \rho \pi r^{2} v^{2}$ and $11.056 \rho^{1.929} \pi r^{2.929} v^{2.929}$ with respect to small, middle and big raindrops respectively.

\section{Dynamic Characteristic and Three Sorts of Numerical Solutions on Real Raindrops}

In above coordinate system, the gravitational force, the buoyancy, the viscous resistance and the Coriolis force may be expressed with three components respectively. Taking the Earth as reference system, substituting the component of forces into the Newton's second law $m a=F_{\mathrm{g}}+F_{\mathrm{r}}+F_{\mathrm{f}}+F_{\mathrm{c}}$, we establish three groups equations of raindrops in above standard coordinate system, namely, from left to right the dynamic equations of small, middle and big raindrops are as follows respectively

$$
\left\{\begin{array} { l } 
{ m \frac { d ^ { 2 } x } { d t ^ { 2 } } = 2 m \omega \operatorname { s i n } \theta \frac { d y } { d t } } \\
{ m \frac { d ^ { 2 } y } { d t ^ { 2 } } = - 2 m \omega ( \frac { d x } { d t } \operatorname { s i n } \theta + \frac { d z } { d t } \operatorname { c o s } \theta ) } \\
{ m \frac { d ^ { 2 } z } { d t ^ { 2 } } = - G \frac { M m } { ( R + z ) ^ { 2 } } + \frac { 4 } { 3 } \pi r ^ { 3 } g \rho } \\
{ + 0 . 0 2 3 \rho ^ { 0 . 5 6 2 4 } \pi r ^ { 1 . 5 6 2 4 } ( \frac { d z } { d t } ) ^ { 1 . 5 6 2 4 } } \\
{ + 2 m \omega \operatorname { c o s } \theta \frac { d y } { d t } } \\
{ \rho = \rho _ { 0 } \operatorname { e x p } ( - m _ { 0 } g z / k T ) } \\
{ T = 2 8 8 . 1 5 - 0 . 0 0 6 5 z }
\end{array} \quad \left\{\begin{array} { l } 
{ m \frac { d ^ { 2 } x } { d t ^ { 2 } } = 2 m \omega \operatorname { s i n } \theta \frac { d y } { d t } } \\
{ m \frac { d ^ { 2 } y } { d t ^ { 2 } } = - 2 m \omega ( \operatorname { s i n } \theta \frac { d x } { d t } + \operatorname { c o s } \theta \frac { d z } { d t } ) } \\
{ m \frac { d ^ { 2 } z } { d t ^ { 2 } } = - G \frac { M m } { ( R + z ) ^ { 2 } } + 0 . 2 5 \rho \pi ^ { 2 } ( \frac { d z } { d t } ) ^ { 2 } } \\
{ + \frac { 4 } { 3 } \pi r ^ { 3 } g \rho + 2 m \omega \operatorname { c o s } \theta \frac { d y } { d t } } \\
{ \rho = \rho _ { 0 } \operatorname { e x p } ( - m _ { 0 } g z / k T ) } \\
{ T = 2 8 8 1 5 - 0 . 0 0 6 5 }
\end{array} \left\{\begin{array}{l}
m \frac{d^{2} x}{d t^{2}}=2 m \omega \sin \theta \frac{d y}{d t} \\
m \frac{d^{2} y}{d t^{2}}=-2 m \omega\left(\sin \theta \frac{d x}{d t}+\cos \theta \frac{d z}{d t}\right) \\
m \frac{d^{2} z}{d t^{2}}=-G \frac{M m}{(R+z)^{2}}+\frac{4}{3} \pi r^{3} g \rho \\
+11.056 \rho^{1.929} \pi r^{2.929}\left(\frac{d z}{d t}\right)^{2.929} \\
+2 m \omega \cos \theta \frac{d y}{d t} \\
\rho=\rho_{0} \exp \left(-m_{0} g z / k T\right) \\
T=288.15-0.0065 z
\end{array}\right.\right.\right.
$$

Numerical Solutions of small raindrops

Table 1. The data on terminal velocity, height, time and migration

Solving the left of Eq. (5) with MATLAB, we get many numerical solutions on small raindrops falling and data comparison as shown in Figure 2 and Table 1. of small raindrops.

\begin{tabular}{ccccccc}
\hline Diameter Terminal & $\begin{array}{c}\text { Time } \\
\text { speed } \\
\text { with } v_{\mathrm{t}} \\
t[\mathrm{~s}]\end{array}$ & $\begin{array}{c}\text { Falling } \\
\text { height with } v_{\mathrm{t}} \\
(4175-z)[\mathrm{m}]\end{array}$ & $\begin{array}{c}\text { Total } \\
\text { falling time } \\
T[\mathrm{~s}]\end{array}$ & $\begin{array}{c}\text { Eastward } \\
\text { migration } \\
y[\mathrm{~m}]\end{array}$ & $\begin{array}{c}\text { Southward } \\
\text { migration } \\
x[\mathrm{~m}]\end{array}$ \\
\hline 0.5 & 2.17 & 0.88 & 1.00 & 1926.1 & 590.11 & 16.02 \\
1.0 & 4.10 & 1.46 & 5.00 & 1018.1 & 300.69 & 8.23 \\
1.4 & 5.60 & 2.05 & 8.00 & 744.6 & 170.77 & 3.20 \\
\hline
\end{tabular}

From the soil erosion in soil and water conservation of the Journal of Climate Applied Meteor(JCA $\mathrm{M})$, based on the verified results of

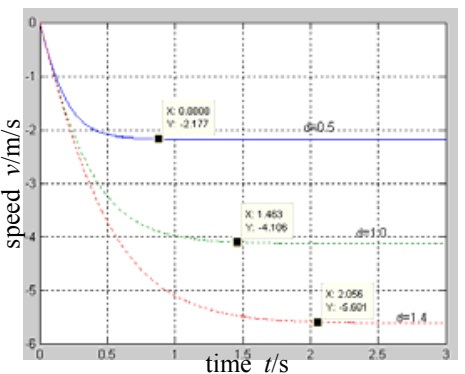

(a). Relations between speed and time

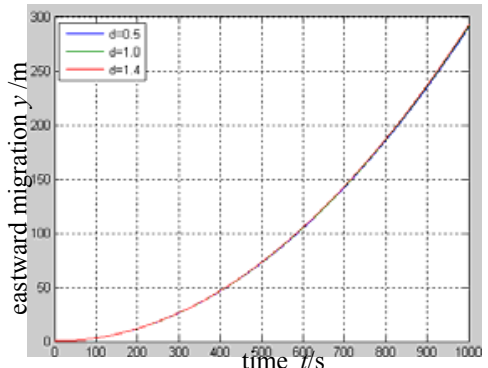

(b). Eastward migration and time.

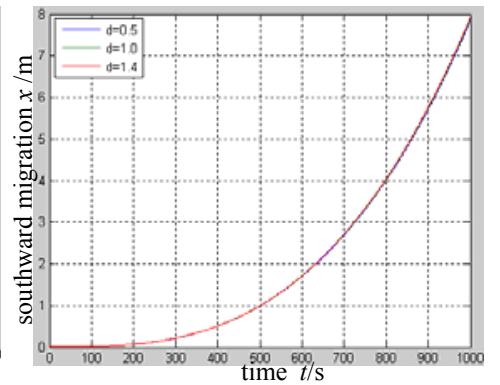

(c). Southward migration and time. numerical Fig.2. Engineering movement characteristics of small raindrops with three different diameters. simulation of raindrops falling ${ }^{[7]}$, above three terminal speeds data are analysed and evaluated with the mean analysis method of paired two-sample in t-test(MAMPTSTT). We get the Poisson coefficient of correlation on two groups of data as 0.86566 . It can be seen that the error on the terminal speeds is not very big, so that the proposed small raindrops model is sufficiently accurate.

\section{Numerical Solutions of Mid-raindrops}

Solving the center Eq.(5) with MATLAB, we get many numerical solutions and typical data on mid-raindrops falling as shown in Figure 3 and Table 2 respectively.

As similar to the above section 3.1, based on the verified results of numerical simulation of mid-raindrops falling from the $\mathrm{JCAM}^{[7]}$, terminal speeds data of mid-raindrops are
Table 2. The data on terminal velocity, height, time and migration of middle raindrops.

\begin{tabular}{ccccccc}
\hline Diameter Terminal & $\begin{array}{c}\text { Time } \\
\text { speed } \\
\text { with } v_{\mathrm{t}} \\
t[\mathrm{~mm}]\end{array}$ & $\begin{array}{c}\text { Falling } \\
v_{\mathrm{t}}[\mathrm{m} / \mathrm{s}]\end{array}$ & $\begin{array}{c}\text { height with } v_{\mathrm{t}}[\mathrm{s}] \\
(4175-z)[\mathrm{m}]\end{array}$ & $\begin{array}{c}\text { Total } \\
\text { falling time } \\
T[\mathrm{~s}]\end{array}$ & $\begin{array}{c}\text { Eastward } \\
\text { migration } \\
y[\mathrm{~m}]\end{array}$ & $\begin{array}{c}\text { Southward } \\
\text { migration } \\
x[\mathrm{~m}]\end{array}$ \\
\hline 2.0 & 6.03 & 1.80 & 8.20 & 700.4 & 150.32 & 2.05 \\
3.0 & 7.39 & 2.33 & 13.20 & 639.3 & 110.36 & 1.52 \\
4.0 & 8.53 & 2.63 & 17.00 & 550.7 & 90.08 & 1.06 \\
\hline
\end{tabular}


analysed and evaluated with the MAMPTSTT, and the Poisson coefficient of correlation on two groups of data (PCCTGD) is 0.70826. Obviously, because of the modicus error on the terminal speeds, the middle raindrops model of Eq.(6) has very good accuracy.

\section{Numerical Solutions of Big Raindrops}

Solving the right of Eq. (5) with MATLAB, we also get many numerical solutions and typical data on big raindrops falling as shown in Figure 4 and

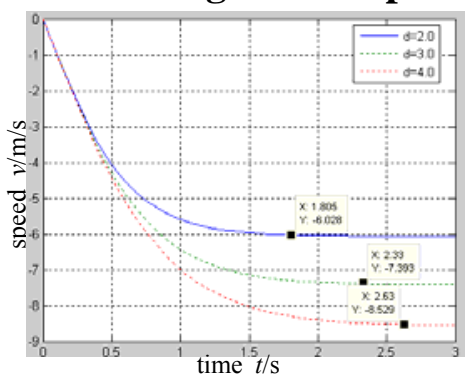

(a). Relations between speed and time.

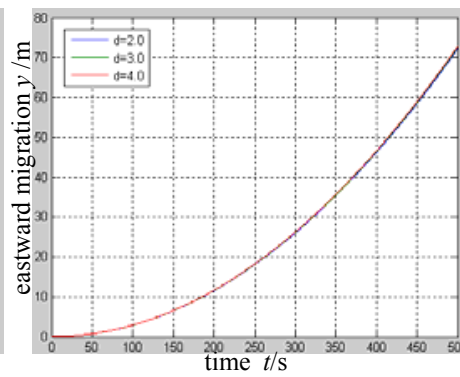

(b). Eastward migration and time.

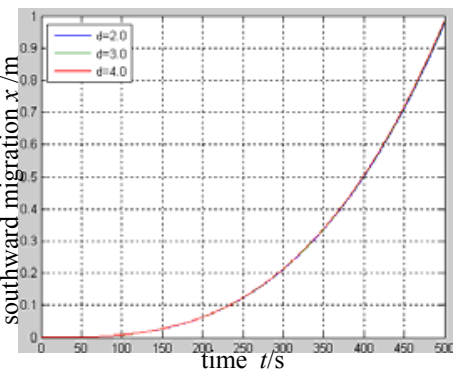

(c). Southward migration and time.

Fig.3. Engineering movement characteristics of middle raindrops with three different diameters.

And so forth the above section 3.1 or 3.2 , based on the verified results of numerical simulation of raindrops falling from the $\mathrm{JCAM}^{[7]}$, terminal speeds data of big raindrops are analysed and evaluated with the MAMPTSTT. According to the PCCTGD 0.79326, we find small error on the terminal speeds, and then a favorable model of real big raindrops.

\section{Conclusion}

In Xi'an region, the viscous resistance is the most important factor influencing

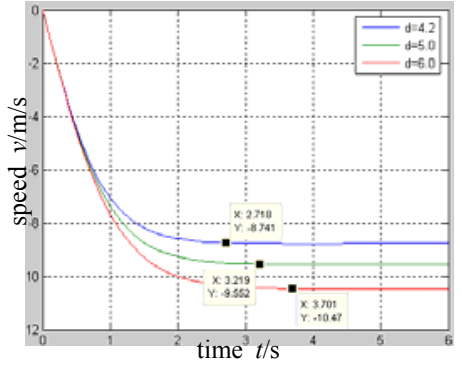

(a). Relations between speed and time.

\begin{tabular}{|c|c|c|c|c|c|c|}
\hline $\begin{array}{c}\text { Diameter } \\
d[\mathrm{~mm}]\end{array}$ & $\begin{array}{c}\text { Terminal } \\
\text { speed } \\
v_{\mathrm{t}}[\mathrm{m} / \mathrm{s}] \\
\end{array}$ & $\begin{array}{c}\text { Time } \\
\text { with } v_{\mathrm{t}} \\
t[\mathrm{~s}]\end{array}$ & $\begin{array}{c}\text { Falling } \\
\text { height with } v_{\mathrm{t}} \\
(4175-z)[\mathrm{m}]\end{array}$ & $\begin{array}{c}\text { Total } \\
\text { falling time } \\
T[\mathrm{~s}]\end{array}$ & $\begin{array}{c}\text { Eastward } \\
\text { migration } \\
y[\mathrm{~m}] \\
\end{array}$ & $\begin{array}{c}\text { Southward } \\
\text { migration } \\
x[\mathrm{~m}] \\
\end{array}$ \\
\hline 4.2 & 8.74 & 2.71 & 22.30 & 537.5 & 75.07 & 0.92 \\
\hline 5.0 & 9.55 & 3.21 & 28.05 & 500.3 & 65.66 & 0.85 \\
\hline 6.0 & 10.47 & 3.70 & 33.01 & 460.7 & 55.46 & 0.78 \\
\hline
\end{tabular}

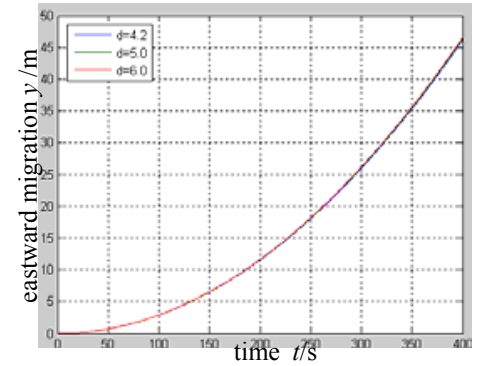

(b). Eastward migration and time.

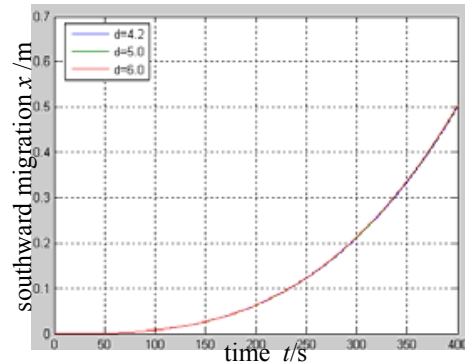

(c). Southward migration and time.

Fig.4. Engineering movement characteristics of big raindrops with three different diameters. The terminal speeds reach the ranges within $(2.1-5.6 \mathrm{~m} / \mathrm{s}),(6.0-8.5 \mathrm{~m} / \mathrm{s})$ and $(8.7-10.5 \mathrm{~m} / \mathrm{s})$ for the small, middle and big raindrops, respectively, and corresponding to the falling height scales of $(1.0-8.0 \mathrm{~m}),(8.2-17.0 \mathrm{~m})$ and $(22.0-33.0 \mathrm{~m})$. The Coriolis force is only factor of eastward and southward falling of raindrops. The eastward migration is more obvious than the southward case, as well as the greater falling height and the longer total falling time and the greater migration. The eastward migration ranges are $(170-590 \mathrm{~m}),(90-150 \mathrm{~m})$ and $(55-75 \mathrm{~m})$ for the small, middle and big raindrops, respectively, and corresponding to the southward migration within $(3.2-16.0 \mathrm{~m}),(1.0-2.1 \mathrm{~m})$ and $(1.7-0.9 \mathrm{~m})$. As per the t-test and Poisson coefficient, three models of real raindrops are favorable.

\section{References}

[1] Y.Q. Qian, S.H. Tao. Journal of Northwestern Agricultural University, Vol. 26(5)(1998) p.20-24

[2] S.B. Qiu, J.H. Chen. Chinese Journal of Radio Science, Vol. 13(1)(1998) p. 88-92 (in Chinese)

[3] H.Z. Song. Journal of Nanyang Teachers College, Vol. 4(6)(2005) p. $701-704$ (in Chinese)

[4] H.M. Wang, H.Y. Li, L.X. Li. Journal of Dezhou University, Vol.19(6)(2003) p.39-41

[5] D.W. Liu, A.L. Yan. Science Technology and Engineering, Vol. 6(9)(2006) p. 1266-1269

[6] P.K. Smolarkiewicz, T.L. Clark. Journal Atmos. Sci., Vol. 42(1985) p.502-522

[7] R.D. Farley, H.D. Orville. Journal of Clim. Appl. Meteor, Vol. 25(1986) p.2104-2035 